\title{
Complete laparoscopic right hemihepatectomy
}

\author{
Jun-Cheng Wang ${ }^{1,2}$, Yao-Jun Zhang ${ }^{1,2}$, Li Xu ${ }^{1,2}$, Min-Shan Chen ${ }^{1,2}$, Zhong-Guo Zhou ${ }^{1,2}$ \\ ${ }^{1}$ Sun Yat-Sen University Cancer Center State, State Key Laboratory of Oncology in South China, Collaborative Innovation Center for Cancer \\ Medicine, Guangzhou 510060, China; ${ }^{2}$ Department of Hepatobiliary Oncology, Sun Yat-Sen University Cancer Center, Guangzhou 510060, China \\ Correspondence to: Zhong-Guo Zhou, MD, PhD. Department of Hepatobiliary Oncology, Sun Yat-Sen University Cancer Center, 651 Dongfeng \\ Road East, Guangzhou 510060, China. Email: zhouzhg@sysucc.org.cn.
}

\begin{abstract}
In this surgery, we employed intrathecal dissection to reveal right hepatic artery and portal vein for blockage of right hepatic inflow, hepatic vein was shown clearly after "down-top" dissection along inferior vena cava under a left-traction. Cavitron ultrasonic surgical aspirator (CUSA) was involved in parenchyma resection, and right hepatic pedicle and hepatic vein were cut off by Endo GIA.
\end{abstract}

Keywords: Laparoscopic; hemihepatectomy

Submitted Jul 20, 2018. Accepted for publication Jul 31, 2018.

doi: $10.21037 /$ tcr.2018.08.05

View this article at: http://dx.doi.org/10.21037/tcr.2018.08.05

\section{Introduction}

Since the first laparoscopic cholecystectomy was performed in 1987, endoscopic surgery has been widely established as a safe and feasible procedure for both benign and malignant diseases $(1,2)$. Comparative studies have demonstrated that laparoscopy is associated with less pain and bleeding, fewer complications, and shorter hospital stay than open liver surgery $(3,4)$. However, due to the unique anatomical structure and technical difficulties, this surgical procedure is limited to specific segmental (segment II, III, IVb, V or VI) or minor anatomic resection $(4,5)$. We have recently showed that, for specific segmental (segment VI, VII, or VIII), laparoscopic hepatectomy with a novel left jackknife position was safe and effective during tumor resection by exposing a sufficient operating field (6). This video (Figure 1) illustrates our technical maneuvers of a totally laparoscopic right hemihepatectomy, highlighting the most relevant technical details essential for extensive laparoscopic liver resection.

\section{Operative techniques}

\section{Operative position and trocar placement}

The patient was placed supinely in the reversed Trendelenburg position. The operator and assistant stood by the patient's right and left flank, respectively. Pneumoperitoneum was established by maintaining the abdominal pressure to $10-12 \mathrm{mmHg}$. Meanwhile, low central venous pressure (CVP) was maintained $(0-5 \mathrm{mmHg})$. Five ports were established in this procedure
(Figure 2). The initial trocar is placed in supra-umbilical and was used as observation port (12-mm, T1, Figure 2). Another 12$\mathrm{mm}$ trocar was inserted $2-3 \mathrm{~cm}$ blow the right costal margin at the midclavicular line as the main operating hole (T2, Figure 2).The other three 5 -mm trocars were placed (I) blow the right costal margin at the anterior axillary line as the subsidiary hole for main operator (T3, Figure 2); (II) the midpoint of xiphoid process and the umbilicus as the main operating hole for assistant (T4, Figure 2); and (III) blow the xiphoid process as the subsidiary hole for assistant (T5, Figure 2).

\section{Surgical approach}

\section{Preliminary liver mobilization}

First, a $30^{\circ}$ laparoscopic camera was introduced into T1 port and a preliminary abdominal exploration was performed. Then, the right liver was mobilized by dividing the round and falciform ligaments back to the level of hepatocaval venous confluence. The coronary, right triangular and hepatorenal ligaments were also divided.

\section{Hilar dissection}

The liver was examined systematically by laparoscopic sonography. Cholecystectomy was then performed. Following the common hepatic duct to the confluence of the right and left hepatic duct, Glisson's pedicle was incised. Then, the biliary convergence was retracted to expose the hepatic artery plane. Dissected the right hepatic artery, and ligated it. The right portal vein was mobilized up to the junction of the right 


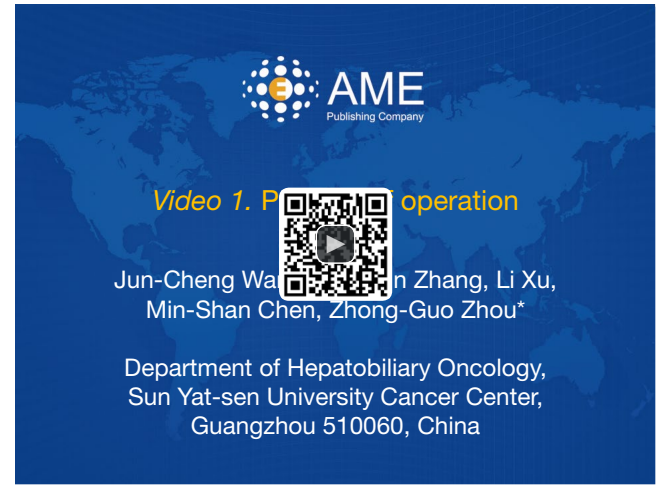

Figure 1 Process of operation (7).

Available online: http://www.asvide.com/article/view/26849

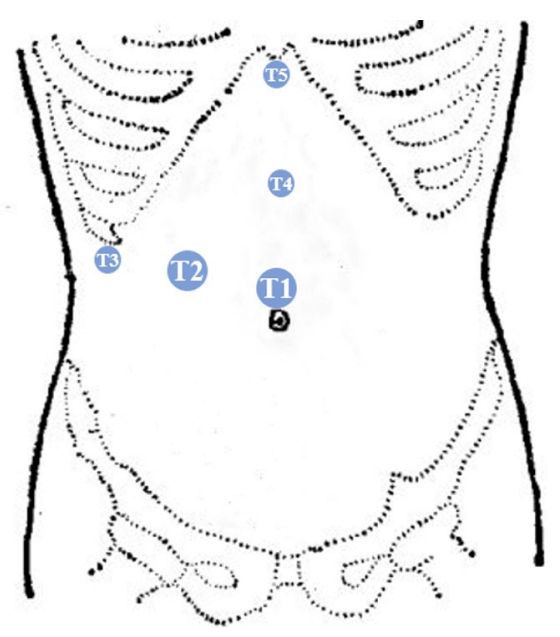

Figure 2 Trocars placement.

and left portal vein, and the right trunk was ligated with suture. Thus, the inflow control was achieved, resulting in ischemic delineation of the right lobe. In addition, a hilar lymph node was detected and removed for pathological examination.

\section{Ligation of short hepatic veins}

The right liver was mobilized completely from right adrenal gland and retroperitoneum, and short hepatic veins draining into the inferior vena cava were clipped. To expose the retrohepatic inferior vena cava plane, a mediastinoscopic gauze was inserted and passed between the right posterior lobe of the liver and inferior vena cava. The gauze then was retracted, mobilizing the right lobe away from the retroperitoneum and diaphragm. The inferior vena cava was dissected in a caudal to cephalad direction. Ultimately, the right hepatic vein was dissected and then ligated with suture.

\section{Parenchymal dissection}

We began liver resection about $0.5-1 \mathrm{~cm}$ inside ischemia line to avoid intraoperative bleeding. Liver parenchyma dissection was performed by harmonic scalpel combined with cavitron ultrasonic dissector (CUSA), while the bipolar electrocoagulation was used to rescue hemostasis. The dissection was continued until the branches of middle hepatic vein were encountered, and those veins were cut off after ligated with surgical clips. Two vascular staplers were introduced, one for dividing the right Glission sheath, the other for dividing the right hepatic vein.

\section{Management of the resection margin}

The margin was carefully checked for any bleeding or bile leakage. Hemostasis was achieved by using bipolar electrocoagulation or Prolene sutures ligation. Any bile leakage from the suspicious bile ducts was ligated using 3-0 Prolene sutures. Hemostatic products were routinely used. The specimen was put in a plastic bag to prevent tumor plantation and taken out through the extended incision of the sub-umbilical port. A drainage tube was placed under the right diaphragm.

\section{Postoperative situation}

Operative time was $270 \mathrm{~min}$, with blood loss estimated at $200 \mathrm{~mL}$. There was no blood transfusion during surgery. Postoperative right pleural effusion was detected and the patient was discharged on the seventh day after surgery. In addition, postoperative pathological results revealed that the lesion was well-differentiated hepatocellular carcinoma.

\section{Comments}

A large number of studies have shown that laparoscopy surgery for liver cancer is safe and feasible, and it has become a routine approach in specialized centers $(8,9)$. However, most laparoscopic liver resection is limited to specific segmental or minor anatomic resections $(4,10)$. Laparoscopic major hepatectomy, especially right hemihepatectomy, are technically demanding, and certainly require a long-term training to acquire adequate expertise.

Based on our previous experience with extensive laparoscopic resections, we formed a procedural approach for right hemihepatectomy. First, we mobilize the liver and dissection of the porta hepatis. To facilitate Ultrasonic examination, a preliminary liver mobilization was performed. The hilar was then dissected to achieve inflow control by ligating the right hepatic artery and right portal vein. In addition, we believe that retraction of the right lobe through a gauze is necessary for the ligation of short hepatic veins. By this means, the inferior venous cava plane was well-exposed, and short hepatic veins were shown and clipped safely. If conditions permit, suture ligation of the 
right hepatic vein is recommended because it can control the outflow of right lobe and facilitate to divide the right hepatic vein by the vascular stapler.

In the second step, we dissection of liver parenchymal and intrahepatic major vessels. Inflow and outflow control were achieved by extraparenchymal methods in the first step, which offers safe and hemostatic division of the parenchymal. In addition, it is similarly importantly to decrease the CVP to reduce bleeding during surgery. Technique of controlled low central venous pressure (CLCVP) was performed during surgery. As illustrated by Machado et al. (11), the dissected parenchymal can be divided into three parts: anterior, middle and posterior. Anterior part contains vessels and is safely dissected with harmonic scalpel in this procedure. CUSA were used to clearly dissect the middle part, which was effective in dissecting the branches of middle hepatic vein to segments V and VIII. For the posterior part, two endoscopic vascular staplers were introduced to divide the right Glisson sheath and right hepatic vein.

Therefore, we demonstrated that extraparenchymal blockage of blood flow and intrahepatic division of major blood vessels was safe and feasible for laparoscopic right hemihepatectomy. Relevant strategy may help surgeons to safely perform this challenging procedure.

\section{Acknowledgments}

Funding: The authors acknowledge and express their deepest gratitude to the participants of this study. This work was supported by the National Natural Science Foundation of China (No. 81602143) and Sun Yat-sen University Cancer Center physician scientist funding (No. 16zxqk04).

\section{Footnote}

Conflicts of Interest: All authors have completed the ICMJE uniform disclosure form (available at http://dx.doi. org/10.21037/tcr.2018.08.05). The authors have no conflicts of interest to declare.

Ethical Statement: The authors are accountable for all aspects of the work in ensuring that questions related to the accuracy or integrity of any part of the work are appropriately investigated and resolved. All procedures performed in study involving human participants were in accordance with the ethical standards of the institutional and/or national research committee(s) and with the Declaration of Helsinki (as revised in 2013). Written informed consent was obtained from the patient for publication of this case report and any accompanying images.

Open Access Statement: This is an Open Access article distributed in accordance with the Creative Commons
Attribution-NonCommercial-NoDerivs 4.0 International License (CC BY-NC-ND 4.0), which permits the noncommercial replication and distribution of the article with the strict proviso that no changes or edits are made and the original work is properly cited (including links to both the formal publication through the relevant DOI and the license). See: https://creativecommons.org/licenses/by-nc-nd/4.0/.

\section{References}

1. Nguyen KT, Gamblin TC, Geller DA. World review of laparoscopic liver resection-2,804 patients. Ann Surg 2009;250:831-41.

2. Wakabayashi G, Cherqui D, Geller DA, et al. Recommendations for laparoscopic liver resection: a report from the second international consensus conference held in Morioka. Ann Surg 2015;261:619-29.

3. Han HS, Shehta A, Ahn S, et al. Laparoscopic versus open liver resection for hepatocellular carcinoma: Case-matched study with propensity score matching. J Hepatol 2015;63:643-50.

4. Pearce NW, Di Fabio F, Teng MJ, et al. Laparoscopic right hepatectomy: a challenging, but feasible, safe and efficient procedure. Am J Surg 2011;202:e52-8.

5. Zhang J, Zhou ZG, Huang ZX, et al. Prospective, singlecenter cohort study analyzing the efficacy of complete laparoscopic resection on recurrent hepatocellular carcinoma. Chin J Cancer 2016;35:25.

6. Chen JC, Zhang RX, Chen MS, et al. Left jackknife position: a novel position for laparoscopic hepatectomy. Chin J Cancer 2017;36:31.

7. Wang JC, Zhang YJ, Xu L, et al. Process of operation. Asvide 2018;5:731. Available online: http://www.asvide. com/article/view/26849

8. Otsuka Y, Tsuchiya M, Maeda T, et al. Laparoscopic hepatectomy for liver tumors: proposals for standardization. J Hepatobiliary Pancreat Surg 2009;16:720-5.

9. Soubrane O, Schwarz L, Cauchy F, et al. A Conceptual Technique for Laparoscopic Right Hepatectomy Based on Facts and Oncologic Principles: The Caudal Approach. Ann Surg 2015;261:1226-31.

10. Gayet B, Cavaliere D, Vibert E, et al. Totally laparoscopic right hepatectomy. Am J Surg 2007;194:685-9.

11. Machado MA, Surjan RC, Makdissi FF. Video: intrahepatic Glissonian approach for pure laparoscopic right hemihepatectomy. Surg Endosc 2011;25:3930-3.

Cite this article as: Wang JC, Zhang YJ, Xu L, Chen MS, Zhou ZG. Complete Laparoscopic right hemihepatectomy. Transl Cancer Res 2018;7(4):1175-1177. doi: 10.21037/ tcr.2018.08.05 